\title{
Analysis on the Relationship Between Internet Use and Students' Academic Engagement
}

\author{
Laura BENCHEA \\ Bucharest University of Economic Studies, Piata Romana, Romania \\ laura.benchea@rei.ase.ro
}

Received date: 23 September 2020; Accepted date: 10 February 2021; Published date: 28 June 2021

Academic Editor: Sorin Burlacu

Copyright (C) 2021. Laura BENCHEA. Distributed under Creative Commons Attribution 4.0 International CC-BY 4.0

\begin{abstract}
The rapid integration of information and communication technologies (ICT) into the educational system (schools and universities) over the latest decades indicates that new technologies bring overall positive inputs into the educational process, advantageously altering the traditional way of teaching and learning. The benefits of the Internet in education have been consistently recognized in the literature (instant access to information, networking, new learning resources), but, at the same time, numerous scientific papers revealed its negative effects associated with the excessive use or misuse which may adversely affect one's psychological health (addiction, cognitive disorders, exhaustion), social life (social isolation) or academic performance (reflected in poor engagement, lower grades or even academic failure). Therefore, the Internet can be considered a double-edged sword, which can either increase or diminish students' academic engagement and, consequently, their educational attainments. In this context, the study aims to explore the dynamics of Internet use among Romanian youth and to assess the impact on their academic engagement.
\end{abstract}

Keywords: Education, Learning, Internet, Academic Engagement.

\section{Introduction}

Over the latest decades, the Internet has gained a significant role in the educational process, being one of the most used technologies for learning, teaching and research purposes. The introduction of the Internet in the educational system was intended to promote learning and knowledge acquisition through the easy access to information and different learning resources. All these useful educational tools came along with opportunities of entertainment and

Cite this Article as: Laura BENCHEA (2021)," Analysis on the Relationship Between Internet Use and Students' Academic Engagement", Journal of e-Learning and Higher Education, Vol. 2021 (2021),

Article ID 237803, DOI: $10.5171 / 2021.237803$ 
distractions which, misused or incorrectly understood, have a negative impact on the educational process and students' psychological development. Based on such observations, this study aims to determine the relationship between the Internet use and student academic engagement of Romanian youth. The hypothesis is that students mainly use the Internet for entertainment (movies, games, news, online shopping) and social media platforms to the detriment of proper online learning. Greater awareness of student practices inside and outside the classroom could inform the development of pedagogical tools meant to assist students' cognitive development while drawing on those practices in a way which makes them more relevant for student learning. Research findings as well as personal observations revealed decreasing student engagement in academic activities because of, among other factors, their intense preoccupations in the online sphere. This issue could inform the implementation of learning experiences that are more appealing to students. Based on my experience and observations, I have developed the following hypothesis which underpins the present study: students who spend more time on online activities (internet) will have less time to study and therefore their academic engagement and performances will diminish.

\section{Research questions:}

1. What do Romanian youth use the Internet for?

2. Are there any gender differences in the Internet use?

3. Is there any relationship between the internet use and the academic engagement of Romanian youth?

\section{Objectives:}

1. To identify students' main purposes and interests for Internet use;
2. To illustrate the positive and negative effects of the Internet usage on youth (from psychological, social and intellectual perspective);

3. To examine the relationship between Internet use and the academic engagement of Romanian youth.

\section{Methodology}

This research is based on a secondary analysis of the data collected in 2014 by the Friederich Ebert Stiftung (FES) - a cultural non-profit institution, at a country level. Based on the data collected, a report entitled "Romanian youth: concerns, aspirations, attitudes and lifestyle" was issued in 2014. The data were collected using face-to-face interviews, questionnaires and focus-groups with Romanian youth (1302 respondents, aged 15-29, from different Romanian regions) with the purpose of identifying their values, lifestyles, aspirations, educational achievements or political implication. For the current study, I selected the data related to the topic, respectively information about the Internet use and their academic engagement (for those who are enrolled in the educational system).

\section{Internet as an instrument for education}

There is a growing literature which studies the use of the Internet for educational purposes, underlying its important role in providing academic and scientific information, as well as social connection and entertainment. It is unquestionable that the Internet has shaped the way how teaching is provided and learning is achieved, and it also stimulated the change of mentalities, opened new opportunities for acquiring and delivering information, and enlarged the access to unlimited knowledge.

\section{The benefits of Internet in education}

Numerous studies have focused on the positive impact that the Internet has on 
teaching and learning. It was invented in the early 1960 with the scope of exchanging information on R\&D in the military and science. Currently, it is the largest information infrastructure, holding more than $\quad 1.8 \quad$ billion websites (www.internetlivestats.com, 2020) and other technological related products.

Supporters of the Internet as an essential tool for nowadays education believe that it provides major benefits in terms of academic performance. It provides an ocean of information on almost any subject nearly instantly. According to Deore (2012), having access to almost any information and the latest news keep students connected to the real world and this helps them make better decisions for their lives. An early and consistent report on the impact of the Internet on education was issued by UNESCO in 2003. Back then the report identified the advantages as well as the drawbacks of the Internet in the education sphere and the scientific work. Among the advantages, the report mentions the quick access to information, data and references, rapidity in information retrieval, networking between participants, access to diverse databases, didactic efficacy by delivering materials through electronic means.

\section{Internet in education: negative outcomes}

\section{Cognitive and psychological effects of Internet usage}

A number of research studies demonstrate that a human's learning capacity may be severely damaged by brain overloading with diverse online stimuli. More information doesn't necessarily imply more knowledge. How do all the ingenious apps we depend on influence us to find and assess the relevant information and to fulfill our cognitive tasks? In 2008, a Dutch psychologist, Cristof van Nimwegen carried out a study using computer-based learning in which two groups of volunteers had to solve a complicated puzzle. One of the two groups received soft-based assistance while the other group were given no help, suggestions or any other assistance to solve the puzzle. Initially, the soft assisted group made more rapid moves but as the game advanced, the skills of the other group developed as they were forced to rely only on their own intellectual capacities. Results showed that those who worked without assistance were able to anticipate the game, to design a strategy, were more focused and eventually identified better solutions. On the other hand, the more the other participants relied on software guidance in task solving, the less they learned and were less capable to rely on their own cognitive abilities. In van Nimwegen's conclusion, the more we "externalize" problem solving to computers, the more we reduce the brain's capacity to build stable structures of knowledge (schemes) which can subsequently be applied in new circumstances (Carr, 2012).

\section{The perils of multitasking}

Web browsing implies an intense form of multitasking because every time one shifts his attention from one subject to another the brain must reorganize, using more mental resources. As Maggie Jackson explains in "Distracted" (2008), a book on multitasking, the brain needs time to switch tasks, to remind the rules needed for the new task and to block the cognitive interference of the previous task, still in force. Even more, a simple exchange between two tasks may significantly increase the cognitive load, hindering thinking and increasing the probability to overlook or misinterpret relevant information (Foerde, Knowlton and Poldrack, 2006).

Studies in the field also emphasize that people tend to move quickly from one web page to another. A longitudinal study conducted by a group of researchers from the University College in London examined two popular research sites that give access to scientific articles, electronic books and other academic tools. They discovered that users 
displayed a "discontinuous form of activity" in which they rapidly jumped from one source to another, reading one or two pages at most from one article or book before moving to another site. "It is apparent that users do not read online in the traditional way; it seems that there emerge new types of reading and people go online to avoid traditional reading" (Carr, 2012). Students developed the ability to rapidly scan the needed information, but the time spent with deep and focused reading constantly diminished. According to Anderson (2009), the reasons why people spend so much time online is that there are numerous benefits in terms of work and pleasure, and it is already too late to retreat in quieter times. On the other hand, Jordan Grafman, a physician specialized in neurological disorders, explained that improvement in the human capacity to solve multiple tasks impedes their deep thinking and creativity (Carr, 2012). Certainly, the Roman philosopher, Seneca, resumed it better 2000 years ago when he asserted that "Being everywhere means being nowhere".

\section{Internet Addiction}

The benefits of the Internet have been highly praised in numerous research papers, but a growing literature has demonstrated its negative effects especially related to its excessive use which adversely affects one's health, social life or academic performance. A study carried out in 2006 (Mafe and Blass cited in Akhter, 2013) showed that university students (aged 19-24) are more at risk of becoming Internet addicted as, during this period, they have more spare time and they are less monitored by their parents.

Akhter (2013) investigated the relationship between Internet addiction and academic performance of university undergraduates. He discovered that the excessive use of the Internet has a negative impact on the academic performance as it increases the probability to miss classes and, consequently, to get lower grades. Good academic results imply physical health, time management and hard work (for exams, assignments or group projects). This is why students who spend much time in online activities have little or no time for studies (Griffith, 2000 cited in Akhter, 2013). Other explanations point out that students lose their concentration most probably as a result of late night Internet sessions (Frangos and Frangos, 2009 cited in Akter, 2013).

Among the most important psychological disorders associated to Internet addiction, psychologists pointed out to depression, anxiety, loneliness and social isolation (Akhter, 2013). One of the most important studies on the relationship between depression and internet addiction was carried out by Young and Rogers in 1998. They discovered that there is a connection between Internet addiction and some characteristics attributed to depressives (low self-esteem, weak motivation, fear of being rejected and need of approval). One reasonable explanation is that the Internet, especially online communication, might help them overcome the interpersonal communication deficit in real life.

\section{Student engagement in the internet era}

The concept of student engagement/involvement was coined out by Astin in 1984 and defined as "the amount of physical and psychological energy that the student devotes to the academic experience. Thus, a highly involved student is one who, for example, devotes considerable energy to studying, spends much time on campus, participates actively in student organizations, and interacts frequently with faculty members and other students." (Astin, 1984). Today, engagement is no longer confined to the time and energy dedicated to educational achievements, but includes investment in collegiate experience, online interactions with peers and involvement in other educational activities.

As social media are conceived as platforms for engagement and because students spend 
much time using these networks, several research studies tried to examine the relationship between Facebook use, for example, and student engagement and how it affects students' success in the academic sphere. A study carried out in 2011 and entitled "Too much face and not enough books: the relationship between multiple indices of Facebook use and academic performance" (Junco, 2011) addressed this issue and found out that students who spend more time on Facebook have less time to study and therefore achieve lower academic performance (reflected in lower grades). These results are consistent with other findings (Astin, 1984) which demonstrate that academic success is dependent upon the time and energy invested in academic work. Therefore, the time spent on social media (Facebook, Instagram) might not be in itself a problem, but it prevents students from engaging more time in studying and research shows that engagement influences academic performance.

There are other studies which demonstrate that the amount of time students spend on Facebook (the most popular social networking) significantly influences their academic success. A survey conducted in the United States (Dahlstrom et al., 2011) on 3000 students reported that $90 \%$ of the college students were using Facebook and this over involvement had a negative impact on their academic performance as they had decreased time to study and a lower attention channeled towards academic activities (Ellore, Niranjan and Brown, 2014).

Data from Internet World Stats (2017) show that, in Romania, Facebook is the social network with an explosive growth over the past years, registering $8,900,000$ users at the end of 2018. Even though not much research has been conducted on how social media impacts students' learning, it is apparent that they have become almost ubiquitous in Romanian universities. Some research shows that the reason why these social networks are so popular among students resides in the positive relation with forming and increasing social capital (Ellison, Steinfield and Lampe, 2011) while others (Valenzuela, Park and Kee, 2009) discovered that there is a relationship between civic participation, social trust and the intensity of Facebook use (studies cited in Junco, 2015).

Related to the relationship between the Internet use and academic engagement, there was a study carried out in 2011 on Romanian students who benefited from a governmental voucher to purchase a computer. The study showed that students used the computers mainly for playing games, therefore little time remained for homework, reading or other educational activities. Consequently, these students registered a decline in their academic achievement, scoring lower grades at Math, English and Romanian (the main subjects studied in schools). The study emphasizes that despite the good intention to achieve educational purposes and increase knowledge, most of the students used their computers for entertainment and this attitude led to lower academic results (Malamud, Pop-Eleches, 2011).

\section{Results}

This research is based on a secondary analysis of the data collected in 2014 by the Friederich Ebert Stiftung (FES) - a cultural non-profit institution, at a country level. The data were collected using face-to-face interviews, questionnaires and focus-groups with Romanian youth (1302 respondents, aged 15-29, from different Romanian regions) with the purpose of identifying their values, lifestyles, aspirations, educational achievements or political implication. For the current study, I selected the data related to the topic, respectively information about the Internet use and their academic engagement (for those who are enrolled in the educational system).

Data show that Romanian youth use the Internet mainly for social networks, but also as a source of information. Those aged over 25 are using the Internet for information related to their jobs or for online shopping. 
Table 1: Main purposes for Internet use

\begin{tabular}{|l|l|}
\hline Work & $23 \%$ \\
\hline $\begin{array}{l}\text { Reading news online / getting } \\
\text { information }\end{array}$ & $20,2 \%$ \\
\hline $\begin{array}{l}\text { Access to social networks (Facebook, } \\
\text { Instagram) }\end{array}$ & $40,4 \%$ \\
\hline Looking up information & $3,4 \%$ \\
\hline E-mail & $1,0 \%$ \\
\hline Watching videos /listening to music & $1,0 \%$ \\
\hline Downloading films/books & $2,0 \%$ \\
\hline Video games & $5,0 \%$ \\
\hline
\end{tabular}

About half $(46,5 \%)$ of the young Romanians who were involved in this study were integrated into an educational structure (school, high school, university, master or PhD). The other half (over 25 years old) graduated at a certain level, most of them entering the job market. According to the survey, the young Romanian people devote little time to individual study. About half of the youth surveyed spend less than two hours per day on educational activities outside the classrooms, and only $21 \%$ study three hours or more per day (Table 2).

Table 2: Time devoted to study per day

\begin{tabular}{|l|l|}
\hline Up to 1 hour & $11,3 \%$ \\
\hline $1-2$ hours daily on average & $12,4 \%$ \\
\hline 2-3 hours daily on average & $11,4 \%$ \\
\hline 3-4 hours daily on average & $6,4 \%$ \\
\hline More than 4 hours daily & $3,4 \%$ \\
\hline DK/NA & $1,5 \%$ \\
\hline Total & $\mathbf{4 6 , 2 \%}$ \\
\hline
\end{tabular}


An interesting aspect derived from the data analysis is that TV and Internet use among the Romanian youth is correlated with some family characteristics such as parents' level of education and the perceived social class they belong to. Briefly, the more educated the parents are or the higher the class they belong to, the lesser time their children spend in front of the TV and the more time for online activities. For example, almost one third $(32,4 \%)$ of the young people interviewed whose fathers have postgraduate studies never watch TV, but almost $30 \%$ of them spend more than 6 hours a day on the Internet. It can be underlined that TV is preferred by young people whose parents have a lower educational level or belong to a disadvantaged social class while the Internet is mostly used by those whose parents have superior educational attainments or belong to a better social class (FES, 2014). A possible explanation could be that poorer families can afford TV stations as compared to computers, the cost of utilization is cheaper and it doesn't require too much knowledge. In addition, the Internet usage is closely related to some liberal professions and their associated educational forms.

Analyzing the gender differences, data show that $30 \%$ of women spend three or more hours per day engaged in individual study as compared to $13 \%$ of men. Moreover, the data illustrate that $50 \%$ more women than men study between two and three hours per day. This outcome along with the extra effort and enthusiasm engaged by girls in accomplishing their educational activities may indicate the gender discrepancy in terms of educational results.

Consistent with other studies (Tsai et al., 2009; Akhter, 2013), the data collected on Romanian youth show that men spend more time than women in online activities (about $43 \%$ of men spend more than 4 hours a day on the Internet as compared to $34 \%$ of women). According to FES (2014), young men usually use the Internet for news or online games while women tend to browse for work related activities or for social media.

Table 3: Gender difference in Internet use

\begin{tabular}{|c|c|c|c|c|}
\hline $\begin{array}{c}\text { Number } \\
\text { of hours } \\
\text { per day }\end{array}$ & $\begin{array}{c}\text { Up to 1 } \\
\text { hour }\end{array}$ & $\begin{array}{c}\text { Up to 2 } \\
\text { hours }\end{array}$ & $\begin{array}{c}\text { Up to 3 } \\
\text { hours }\end{array}$ & $\begin{array}{c}\mathbf{4} \text { hours or } \\
\text { more }\end{array}$ \\
\hline Men & $12,4 \%$ & $19,2 \%$ & $25,7 \%$ & $\mathbf{4 2 , 7 \%}$ \\
\hline Women & $19,4 \%$ & $20,9 \%$ & $25,5 \%$ & $\mathbf{3 3 . 9 \%}$ \\
\hline
\end{tabular}

Related to the academic results, the average score obtained by the interviewed in the previous year is 8.35 (FES, 2014). The best average score (8.4) is obtained by the group associated with undergraduates and graduates (college and master students, aged 20-24). On average, women in the sample got 0,6 points more than men, a statistically significant difference (the average female score is 8.63 while male got 8.01 in the year before the study).

The hypothesis which underpins the present study is that students who spend more time in online activities (internet) will have less time to study and therefore their academic engagement and performances will diminish. In order to establish if there is any 
relationship between the Internet use and student academic engagement, I had as reference the theory of student engagement elaborated by Austin (1984) and the analysis of the data presented in the current study. According to Austin, a student's involvement in the academic work, for example, can be measured quantitatively (how many hours the student spends studying - the theory suggests that "the extent to which students can achieve particular developmental goals is a direct function of the time and effort they devote to activities designed to produce these gains"). In essence, the more time students spend on learning, the more they learn and the better their marks are. In order to identify if there is any relationship between the time spent on the Internet and the academic engagement (measured in time devoted to studying), two variables are measured and the relationship between them: the average number of hours spent a day on the Internet and the grade point average of the previous year. Figure 1 indicates that there is a negative correlation between the two variables analyzed (Pearson Coefficient, -.062).

Correlations

\begin{tabular}{|c|c|c|c|}
\hline & & $\begin{array}{l}\text { How many } \\
\text { hours a day } \\
\text { on average do } \\
\text { you spend on } \\
\text { the Internet? }\end{array}$ & $\begin{array}{c}\text { What was } \\
\text { your grade } \\
\text { point average } \\
\text { last year? }\end{array}$ \\
\hline $\begin{array}{l}\text { How many hours a day on } \\
\text { average do you spend on } \\
\text { the Internet? }\end{array}$ & $\begin{array}{l}\text { Pearson Correlation } \\
\text { Sig. (2-tailed) } \\
N\end{array}$ & $\begin{array}{r}1 \\
1181\end{array}$ & $\begin{array}{r}-.062 \\
.167 \\
502\end{array}$ \\
\hline $\begin{array}{l}\text { What was your grade } \\
\text { point average last year? }\end{array}$ & $\begin{array}{l}\text { Pearson Correlation } \\
\text { Sig. (2-tailed) } \\
\text { N }\end{array}$ & $\begin{array}{r}-.062 \\
.167 \\
502\end{array}$ & $\begin{array}{r}1 \\
518\end{array}$ \\
\hline
\end{tabular}

Figure 1: Correlation between the time spent on the Internet and the average grade point

Therefore, the analysis supports the hypothesis and shows that the more time young people spend on the Internet (for noneducational purposes), the lower their grades would be and consequently their overall academic performance would decrease.

\section{Conclusions}

The rapid expansion of information and communication technologies (ICT) in the educational field (schools and universities) over the latest decades demonstrate that new technologies are highly integrated within the educational process, with a huge impact on learning and teaching. The purpose of this study was to analyze the dynamics of
Internet use among Romanian youth and to assess the relationship between the Internet use and their academic engagement. In this respect, I have formulated three research questions:

RQ1: What do Romanian youth use mostly the Internet for?

RQ2: Are there any gender differences in the Internet use?

RQ3: Is there any relationship between the internet use and the academic engagement of Romanian youth? 


\section{Research question 1:}

Data show that Romanian youth use the Internet mainly for social networks, but also as a source of information. Those aged 25 and more are using the Internet for acquiring information related to their work or for online shopping. Not surprisingly, 9 out of 10 teenagers use the Internet for social media platforms (Facebook and, more recently, Instagram). These findings reveal that, irrespective of age, Romanian youth mostly use the Internet for entertainment purposes in the detriment of scientific and educational work, and this prevents them from achieving better academic results. Other previous research in the field (Ravizza, Hambrick and Fenn, 2014) showed that the Internet used for non-academic purposes influences learning and the overall student's academic performance.

\section{Research question 2:}

The data collected on Romanian youth show that men spend more time than women in online activities (about $43 \%$ of men spend more than 4 hours a day on the Internet as compared to $34 \%$ of women). Moreover, young men usually use the Internet for news or online games while women tend to use it for social media or for work related activities.

\section{Research question 3:}

Data analysis indicates that there is a negative correlation between the Internet use and the academic results of Romanian youth, which leads to the conclusion that the more time is spent on online activities, the lower the academic results would be. These findings are supported by other studies (Astin, 1984; Akhter, 2013) which demonstrated that the more time students spend on the Internet, the possibility to get lower grades is higher, as there is no much time left to invest in studies or other educational activities.

\section{References}

- Akhter, N. (2013) 'Relationship between internet addiction and academic performance among university undergraduates', Educational Research and Reviews, 8 (19), 1793-1796.

- Astin, A. (1984) 'Student involvement: a developmental theory for higher education', Journal of College Student Personnel, 25(4), 297-308.

- Carr, N. (2012) Superficialii: Efectele internetului asupra creierului uman, Publica, Bucharest.

- Deore, K.V. (2012) 'The Educational Advantage of Using Internet', International Educational E-Journal, 1 (2), 111-112.

- Ellore, S.B., Niranjan, S. and Brown, U.J. (2014) 'The influence of internet usage on academic performance and face-toface communication', Journal of Psychology and Behavioral Science, 2 (2), 163-186.

- Foerde, K., Knowlton, B.J. and Poldrack, R.A. (2006) 'Modulation of competing memory systems by distraction', Proceedings of the national Academy of Sciences of the United States of America, 103 (31), 11778-11783.

- Friedrich-Ebert-Stiftung (FES) Raport (2014) 'Tineri in Romania: griji, aspiraţii, atitudini şi stil de viaţa' Raport de cercetare realizat de Centrul de Sociologie Urbană şi Regională-CURS pentru Friedrich-Ebert-Stiftung Romania.

- Internet World Stats, Usage and Population Statistics. [Online], [Retrieved August 10, 2020] http://www.internetworldstats.com/eu/ ro.htm

- Junco, R. (2011) 'Too much face and not enough books: the relationship between multiple indices of Facebook use and academic performance', Computers in Human Behavior, 28, 187-198.

- Junco, R. (2015) 'Student class standing, Facebook use, and academic 
performance', Journal of Applied Developmental Psychology, 36, 18-29.

- Jackson, M. (2008) Distracted: The Erosion of Attention and Coming Dark Age, Prometheus, New York.

- Malamud, O. and Pop-Eleches, C. (2010) 'Home computer use and the development of human capital', The Quarterly Journal of Economics, 126, 9871027.

- Nimwegen, C. (2008) The Paradox of the Guided User: Assistance Can be Countereffective, Uttrecht University.

- Ravizza, M., Hambrick, D.Z. and Fenn, K.M. (2014) 'Non-academic internet use in the classroom is negatively related to classroom learning regardless of intellectual ability', Computers and Education, 78, 109-114.

- United Nations Educational, Scientific and Cultural Organization (UNESCO) (2013), "Internet in Education. Support Materials for Educators", UNESCO Institute for Formation Technologies in Education, Moscow [Online], [Retrieved September 12, 2020], http://unesdoc.unesco.org/images/0013 /001330/133023e.pdf

- Young, K.S. and Rogers, C. (1998) 'The relationship between depression and internet addiction', Cyber- Psychology \& Behavior, 1(1), 25-28. 